\title{
Genipin inhibits the growth of human bladder cancer cells via inactivation of PI3K/Akt signaling
}

\author{
ZHENG LI $^{1}$, TIAN-BIAO ZHANG ${ }^{2}$, DONG-HUI JIA ${ }^{2}$, WEN-QI SUN ${ }^{1}$, \\ CHAO-LIANG WANG ${ }^{2}$, AO-ZHENG GU ${ }^{1}$ and XIAO-MING YANG ${ }^{2}$ \\ ${ }^{1}$ Department of Urology, Nanyang City Center Hospital, Nanyang, Henan 473009; ${ }^{2}$ Department of Urology, \\ The First Affiliated Hospital of Zhengzhou University, Zhengzhou, Henan 450000, P.R. China
}

Received November 17, 2015; Accepted May 23, 2017

DOI: $10.3892 / \mathrm{ol} .2017 .7588$

\begin{abstract}
Genipin, a natural compound derived from the fruit of Gardenia jasminoides, possesses numerous biological properties. The aim of the present study was to investigate the anticancer effects of genipin in human bladder cancer. T24 and 5637 bladder cancer cells were treated with different concentrations of genipin $(0-200 \mu \mathrm{M})$ and tested for cell viability, colony formation, cell cycle progression and apoptosis. A xenograft model of bladder cancer was established to determine the anticancer effect of genipin in vivo. The involvement of the phosphoinositide-3 kinase (PI3K)/Akt pathway in the action of genipin was examined. Genipin treatment significantly inhibited the viability and clonogenic growth of bladder cancer cells and inhibited the growth of T24 xenograft tumors, compared with vehicle controls $(\mathrm{P}<0.05)$. Genipin-treated cells exhibited a cell cycle arrest at the G0/G1-phase, which was accompanied by a deregulation of numerous cell cycle regulators. Genipin-treated cells demonstrated a significant increase in the percentage of apoptotic cells, loss of mitochondrial membrane potential, Bax translocation to the mitochondria and the release of cytochrome $c$ to the cytosol. Additionally, genipin treatment significantly $(\mathrm{P}<0.05)$ reduced the phosphorylation levels of PI3K and Akt in bladder cancer cells. Importantly, genipin-mediated anticancer effects were reversed by the overexpression of constitutively active Akt. In conclusion, to the best of our knowledge, the present study demonstrates for the first time the growth inhibitory effects of genipin in bladder cancer cells, and indicates its potential as a natural anticancer agent for bladder cancer.
\end{abstract}

Correspondence to: Dr Xiao-Ming Yang, Department of Urology, The First Affiliated Hospital of Zhengzhou University, 1 Jianshe East Road, Erqi, Zhengzhou, Henan 450000, P.R. China

E-mail: 2667234301@qq.com

Key words: apoptosis, bladder cancer, cell cycle arrest, growth, natural compound

\section{Introduction}

Bladder cancer is the most common malignancy of the urinary tract and the 14th leading cause of cancer-associated mortality worldwide $(1,2)$. In Western countries, bladder cancer ranks the 4th most frequently diagnosed cancer (3). Multidisciplinary treatment approaches, including surgery, chemotherapy and radiation are available for bladder cancer. Despite advances in diagnosis and treatment, the prognosis, particularly for muscle-invasive disease, remains poor, with a 5-year overall survival of $30-50 \%(4,5)$. Therefore, the development of novel effective therapeutic methods for bladder cancer is of clinical significance.

The phosphoinositide-3 kinase/protein kinase B (PI3K/Akt) pathway has a pivotal role in tumor growth and development (6). Depletion of ubiquitin-conjugating enzyme E2T was found to inhibit the proliferation and invasion of osteosarcoma cells (7). It has been reported that activation of PI3K/Akt signaling contributes to Derlin-1-mediated malignant phenotype in muscle invasive bladder cancer cells (8). Inhibition of PI3K/Akt signaling accounts for the induction of death in bladder cancer cells by combination treatment with rapamycin and resveratrol (9). These studies suggest that the PI3K/Akt pathway is an important target for anticancer treatment.

Genipin, a natural compound derived from the fruit of Gardenia jasminoides, has demonstrated various biological properties including anti-inflammatory (10), anti-oxidative (11), anti-diabetic (12), anti-thrombotic (13), and neuroprotective (14) activities. Previous studies indicate that genipin also exhibits a broad range of anticancer activities in different types of human cancer cells $(15,16)$. For instance, genipin has been suggested to suppress hepatocellular carcinoma metastasis through the inhibition of matrix metalloproteinase-2 activity (15). However, few studies have explored the biological activity of genipin in bladder cancer.

The present study aimed to investigate the effects of genipin on cell growth, cell cycle progression and apoptosis in human bladder cancer. Considering the importance of the PI3K/Akt pathway in tumor progression $(6,7)$, it was also investigated whether this signaling pathway is involved in the action of genipin. 


\section{Materials and methods}

Antibodies. The primary antibodies used in western blot analysis were as follows: Rabbit anti-cyclin D1 (catalog no. 2922), rabbit anti-cyclin-dependent kinase (CDK)2 (catalog no. 2546), rabbit anti-CDK4 (catalog no. 12790), mouse anti-cytochrome $c$ (catalog no.12963), rabbitanti-phospho-PI3K (catalog no.4228), rabbit anti-PI3K (catalog no. 4257), mouse anti-phospho-Akt (catalog no. 12694), and mouse anti-Akt (catalog no. 2920) (all from Cell Signaling Technology, Inc., Danvers, MA, USA), mouse anti-cyclin-dependent kinase inhibitor 1 (p21; catalog no. sc-136020), rabbit anti-cyclin-dependent kinase inhibitor 1B (p27; catalog no. sc-528), mouse anti- $\beta$-actin (catalog no. sc-81178), mouse anti-B-cell lymphoma 2-like protein 4 (Bax; catalog no. sc-20067) (all from Santa Cruz Biotechnology, Inc., Dallas, TX, USA), and rabbit anti-Heat shock protein 60 (catalog no. ab46798; Abcam, Cambridge, UK). Horseradish peroxidase (HRP)-conjugated secondary antibodies were purchased from Santa Cruz Biotechnology, Inc.

Cell culture and genipin treatment. The human bladder cancer T24 and 5637 cell lines and the immortalized normal human uroepithelial SV-HUC-1 cell line were purchased from the Type Culture Collection of Chinese Academy of Sciences (Shanghai, China). They were cultured in Dulbecco's modified Eagle's medium (DMEM) supplemented with $10 \%$ fetal bovine serum (FBS), penicillin (100 U/ml), and streptomycin $(100 \mu \mathrm{g} / \mathrm{ml})$ (all from Invitrogen; Thermo Fisher Scientific, Inc., Waltham, MA, USA) at $37^{\circ} \mathrm{C}$ in a humidified $5 \% \mathrm{CO}_{2}$ atmosphere. Cells were treated with genipin (Sigma-Aldrich; Merck KGaA, Darmstadt, Germany), which was dissolved in $0.1 \%$ dimethyl sulfoxide (DMSO; Sigma-Aldrich; Merck KGaA). DMSO-treated cells were used as a vehicle control.

Cell transfection. A constitutively active Akt construct (Myr-Akt plasmid) and empty vector were purchased from AddGene (Cambridge, MA, USA). Cells were transfected with $0.3 \mu \mathrm{g}$ Myr-Akt or vector using Lipofectamine $2000^{\circledR}$ (Invitrogen; Thermo Fisher Scientific, Inc.), according to the manufacturer's instructions. At $24 \mathrm{~h}$ post-transfection, cells were exposed to genipin for additional $48 \mathrm{~h}$ prior to cell viability and apoptosis analysis. For each condition, three replicates were performed.

Cell viability assay. Cells were plated in 96-well plates at a density of $2 \times 10^{4}$ cells/well and incubated with different concentrations $(10,30,60,100$, and $300 \mu \mathrm{M})$ of genipin for $48 \mathrm{~h}$. DMSO-treated cells were used as a control. Each assay was performed in quadruplicate. Cell viability was measured using the MTT assay. Briefly, cells were added with MTT $(0.5 \mathrm{mg} / \mathrm{ml}$; Sigma-Aldrich; Merck KGaA) and allowed to incubate for $4 \mathrm{~h}$ at $37^{\circ} \mathrm{C}$. Following removal of MTT, the resulting formazan was dissolved in DMSO. Absorbance was measured at $570 \mathrm{~nm}$ using a microplate reader (xMark; Bio-Rad Laboratories, Inc., Hercules, CA, USA).

Clonogenic growth assay. T24 and 5637 cells $\left(5 \times 10^{3}\right.$ cells/well) were seeded in triplicate onto 6-well plates and treated with 30 or $60 \mu \mathrm{M}$ of genipin or DMSO (vehicle control) on the following day. DMEM containing genipin was renewed every 3 days. Following 10 days of culture, cells were stained with $0.5 \%$ crystal violet (Sigma-Aldrich; Merck KGaA). Colonies (>50 cells) were counted in 10 independent microscopic fields (magnification, $\mathrm{x} 40$ ) using an inverted microscope.

Animal experiments. A total of 12 athymic male BALB/c (nu/nu) mice, 4 to 6 weeks old and weighing 16-20 g, were obtained from the Animal Center of the Chinese Academy of Medical Science (Beijing, China). The mice were housed 4 per cage at $22^{\circ} \mathrm{C}$ and $80 \%$ humidity in a 12-h light/dark cycle with access to food and water ad libitum. Mice were injected subcutaneously in the left flank with $4 \times 10^{6} \mathrm{~T} 24$ cells. When xenograft tumors reached a diameter of $\sim 5 \mathrm{~mm}$, the mice were divided into 3 groups ( $\mathrm{n}=4$ for each group) and DMSO (vehicle control) or genipin (20 and $50 \mathrm{mg} / \mathrm{kg}$ ) was administered intraperitoneally three times/week for 4 weeks. The tumors were measured every week with microcalipers. Tumor volume was calculated using the following equation: Tumor volume $\left(\mathrm{mm}^{3}\right)=1 / 2 \mathrm{x}$ (tumor length) $\mathrm{x}$ (tumor width) $)^{2}$. Mice were sacrificed 5 weeks after cell injection and tumors were resected and weighted. Animal experiments were approved by the Institutional Animal Care and Use Committee of Chinese Academy of Medical Science. Animal care and treatment were performed in accordance with the international guidelines for laboratory animals use (https://www.apa.org/science/leadership/care/guidelines.aspx).

Cell cycle and apoptosis analysis. Cell cycle distribution was determined by flow cytometry following staining with propidium iodide (PI). Briefly, subsequent to 30 or $60 \mu \mathrm{g}$ of genipin or DMSO (vehicle control) for $48 \mathrm{~h}$ at $37^{\circ} \mathrm{C}, \mathrm{T} 24$ and 5637 cells were collected and fixed in $70 \%$ ethanol overnight at $4{ }^{\circ} \mathrm{C}$. The cells were resuspended in staining solution containing $0.05 \mathrm{mg} / \mathrm{ml}$ PI and $7 \mathrm{U} / \mathrm{ml}$ RNase A (Sigma-Aldrich; Merck $\mathrm{KGaA}$ ) for $30 \mathrm{~min}$ at $37^{\circ} \mathrm{C}$. Stained cells were analyzed by a flow cytometer (FACSCanto II; BD Biosciences, San Jose, CA, USA) with FlowJo software version 7.6.1 (TreeStar, Inc., Ashland, OR, USA). Cell apoptosis was examined using the Annexin V-fluorescein isothiocyanate (FITC) Apoptosis Detection kit (Beyotime Institute of Biotechnology, Haimen, China), as per the manufacturer's instructions. Following incubation with Annexin V-FITC and PI, T24 and 5637 cells were analyzed by flow cytometry using FlowJo software version 7.6.1. Each assay was performed in triplicate.

Preparation of protein samples. For preparation of the whole cellular lysates, cells were suspended in radioimmunoprecipitation assay buffer (Beyotime Institute of Biotechnology, Inc.) containing protease inhibitors on ice for $15 \mathrm{~min}$. For extraction of mitochondrial and cytosolic fractions, a commercial mitochondria/cytosol fractionation kit (Beyotime Biotechnology, Inc.) was used. Briefly, cells were suspended in ice-cold cytosolic separation buffer containing protease inhibitors for $15 \mathrm{~min}$ and centrifuged at $800 \mathrm{x}$ g for $5 \mathrm{~min}$ at $4^{\circ} \mathrm{C}$. The supernatant was centrifuged at $12,000 \mathrm{xg}$ for $30 \mathrm{~min}$ at $4^{\circ} \mathrm{C}$ to obtain the cytosolic fraction. The pellet was resuspended in mitochondrial separation buffer for $30 \mathrm{~min}$ and then centrifuged at $10,000 \mathrm{x}$ g for $10 \mathrm{~min}$ at $4^{\circ} \mathrm{C}$ to obtain the mitochondrial fraction. Total protein concentrations were determined using 
a Pierce Bicinchoninic Acid Protein Assay kit (Thermo Fisher Scientific, Inc.).

Western blot analysis. Whole and fractionated cell lysates (50 $\mu \mathrm{g}$ total protein per lane) were mixed with loading buffer and subjected to $12 \%$ SDS-PAGE and transferred onto polyvinylidene fluoride membranes. Membranes were blocked with $5 \%$ fat-free milk in TBS containing $0.05 \%$ Tween-20 for $1 \mathrm{~h}$ at room temperature and incubated with primary antibodies overnight at $4^{\circ} \mathrm{C}$. All primary antibodies were diluted to 1:500. Subsequent to washing three times (10 min for each time), the membranes were incubated with HRP-conjugated secondary antibodies (dilution at 1:3,000) for $1 \mathrm{~h}$. Membranes were developed with enhanced chemiluminescence reagents (Amersham Biosciences; GE Healthcare, Chicago, IL, USA). Densitometric analysis of protein signals was conducted with Quantity One software version 4.6.2 (Bio-Rad Laboratories). Each assay was performed in triplicate.

Assessment of mitochondrial membrane potential $(\Delta \psi m)$. Measurement of $\Delta \psi \mathrm{m}$ was performed using the fluorescent probe JC-1, as previously described (17). At low $\Delta \psi \mathrm{m}, \mathrm{JC}-1$ exists primarily in a monomeric form and produces green fluorescence. At high $\Delta \psi \mathrm{m}, \mathrm{JC}-1$ aggregates in intact mitochondria and yields red fluorescence. In brief, T24 and 5637 cells were incubated for $30 \mathrm{~min}$ at $37^{\circ} \mathrm{C}$ with $2 \mu \mathrm{M} \mathrm{JC}-1$ (Molecular Probes, Inc.; Thermo Fisher Scientific, Inc.). Cells were collected and analyzed by the FACSCanto II flow cytometer using FlowJo software version 7.6.1. Results are expressed as the red/green fluorescence intensity ratio; whose reduction indicates loss of $\Delta \psi \mathrm{m}$.

Statistical analysis. Data are presented as the mean \pm standard deviation, and were analyzed using one-way analysis of variance followed by pair-wise comparisons with Tukey's post-hoc test. $\mathrm{P}<0.05$ was considered to indicate a statistically significant difference.

\section{Results}

Genipin exerts growth suppressive effects on bladder cancer cells. Genipin treatment for $48 \mathrm{~h}$ resulted in a concentration-dependent inhibition of the viability of T24 and 5637 bladder cancer cells, compared with the vehicle control (Fig. 1A). In contrast, $\leq 60 \mu \mathrm{M}$ genipin did not exhibit a significant effect on the viability of non-malignant uroepithelial SV-HUC-1 cells. These results suggested that a low concentration of genipin was selectively cytotoxic to bladder cancer cells. In the following experiments, genipin was used at a final concentration of 30 or $60 \mu \mathrm{M}$ unless indicated otherwise.

Next, the effect of genipin on clonogenic growth of bladder cancer cells was determined. As demonstrated in Fig. 1B, exposure to genipin significantly decreased the colony formation in T24 and 5637 cells by 2-3-fold. The in vivo antitumor effect of genipin on the growth of T24 xenograft tumors was also examined in nude mice. Compared to the DMSO-treated group, genipin treatment significantly inhibited the growth of T24 xenograft tumors $(\mathrm{P}<0.05$; Fig. $1 \mathrm{C})$. Genipin at the dose of $50 \mathrm{mg} / \mathrm{kg}$ caused significantly greater tumor suppression
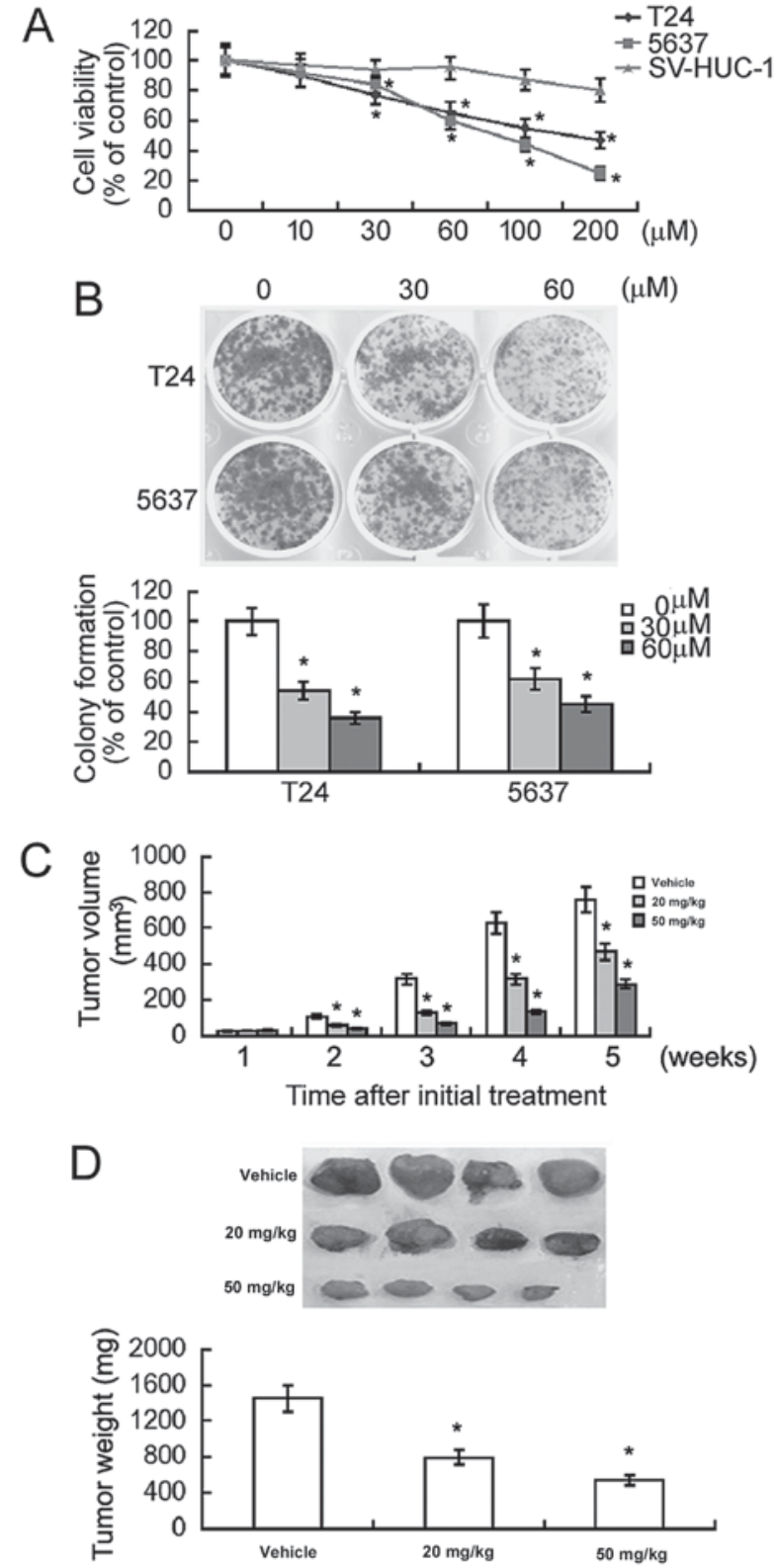

Figure 1. Genipin exerts growth suppressive effects against bladder cancer cells. (A) MTT assay was performed to measure the viability of cells exposed to different concentrations $(0-200 \mu \mathrm{M})$ of genipin for $48 \mathrm{~h}$. (B) The clonogenic growth of cells with or without genipin treatment $(30$ or $60 \mu \mathrm{M})$ was examined following 10 days of culture. Magnification, x40. (C and D) Mice were injected subcutaneously with T24 cells. When xenograft tumors reached a diameter of $\sim 5 \mathrm{~mm}$, dimethyl sulfoxide (vehicle control) or genipin (20 and $50 \mathrm{mg} / \mathrm{kg}$ ) was administered intraperitoneally to the mice. (C) Tumor volume was determined every week up to 5 weeks following initial genipin treatment. (D) At the end of the experiment, animals were sacrificed and tumors were excised and weighed. ${ }^{*} \mathrm{P}<0.05$ vs. vehicle-treated cells.

compared with $20 \mathrm{mg} / \mathrm{kg}$ genipin. At the end of the experiment, the tumor weight was reduced by $>60 \%$ in the genipin (50 mg/kg)-treated group (Fig. 1D). These results confirmed the growth suppressive effects of genipin in bladder cancer.

Genipin induces G0/G1 cell cycle arrest in bladder cancer cells. Flow cytometric analysis revealed that genipin-treated T24 and 5,637 cells exhibited a marked increase in the percentage of cells in the G0/G1 phase and a concomitant reduction in the percentage of $\mathrm{S}$ phase cells (Fig. 2A). The 
percentage of cells in the $\mathrm{G} 2 / \mathrm{M}$ phase was comparable between genipin-treated and DMSO-treated cells. Western blot analysis demonstrated that genipin treatment significantly reduced the expression levels of cyclin D1, CDK2 and CDK4 in T24 and 5,637 cells (Fig. 2B). By contrast, the levels of the CDK inhibitors (p21 and p27) were significantly raised in response to genipin exposure.

Genipin promotes apoptosis in bladder cancer cells via the mitochondrial pathway. Annexin V/PI staining analysis demonstrated that genipin treatment resulted in a significant increase in the percentage of Annexin V-positive apoptotic cells, compared with DMSO treatment $(\mathrm{P}<0.05$; Fig. $3 \mathrm{~A})$. Subsequent to treatment with $60 \mu \mathrm{M}$ genipin, the percentage of apoptotic cells increased from $4.5 \pm 0.9$ to $34.6 \pm 2.1 \%$ in T24 cells and from $3.9 \pm 0.8$ to $28.5 \pm 2.4 \%$ in 5637 cells. To test the involvement of the mitochondrial pathway in genipin-mediated apoptosis, $\Delta \psi \mathrm{m}$, Bax translocation into mitochondria and the release of mitochondrial cytochrome $c$ were measured. As demonstrated in Fig. 3B, there was $70-80 \%$ loss in $\Delta \psi \mathrm{m}$ in the cells treated with $60 \mu \mathrm{M}$ genipin, compared with DMSO-treated controls $(\mathrm{P}<0.05)$. Additionally, genipin-treated cells exhibited increased Bax and decreased cytochrome $c$ expression in the mitochondrial fractions, compared with control cells $(\mathrm{P}<0.05$; Fig. 3C). Additionally, there was decreased Bax and increased cytochrome $c$ expression in the cytoplasmic fractions of genipin-treated cells (Fig. 3C). These results suggest that genipin-induced apoptosis involves mitochondrial damage and cytochrome $c$ release.

Inactivation of PI3K/Akt signaling mediates genipin-induced anticancer effects. Finally, the potential involvement of PI3K/Akt signaling in the anticancer activity of genipin was examined. Western blot analysis suggested that genipin treatment significantly $(\mathrm{P}<0.05)$ reduced the phosphorylation levels of PI3K and Akt in T24 and 5637 cells, compared to DMSO-treated cells (Fig. 4A). Of note, overexpression of constitutively active Akt significantly $(\mathrm{P}<0.05)$ increased the viability (Fig. 4B) and inhibited apoptotic response (Fig. 4C) in genipin-treated T24 and 5,637 cells.

\section{Discussion}

Natural phytochemicals have attracted increasing attention in cancer therapy due to their broad anticancer activity and low cytotoxicity in normal cells $(14,18)$. Genipin has demonstrated anticancer properties in different types of cancers such as hepatocellular carcinoma (15) and colon cancer cells (16). The data of the present study indicated that this natural compound also exerted anticancer effects against bladder cancer cells. Genipin treatment significantly inhibited the viability and clonogenic growth of bladder cancer cells in vitro. Notably, a low concentration of genipin $(\leq 60 \mu \mathrm{M})$ was selectively cytotoxic to bladder cancer cells, but not non-malignant uroepithelial cells. A previous study also indicates the low cytotoxicity of genipin to normal cells (19). In vivo studies additionally confirmed the inhibitory effect of genipin on the growth of bladder cancer xenografts. Therefore, genipin may represent a promising chemotherapeutic agent for bladder cancer.
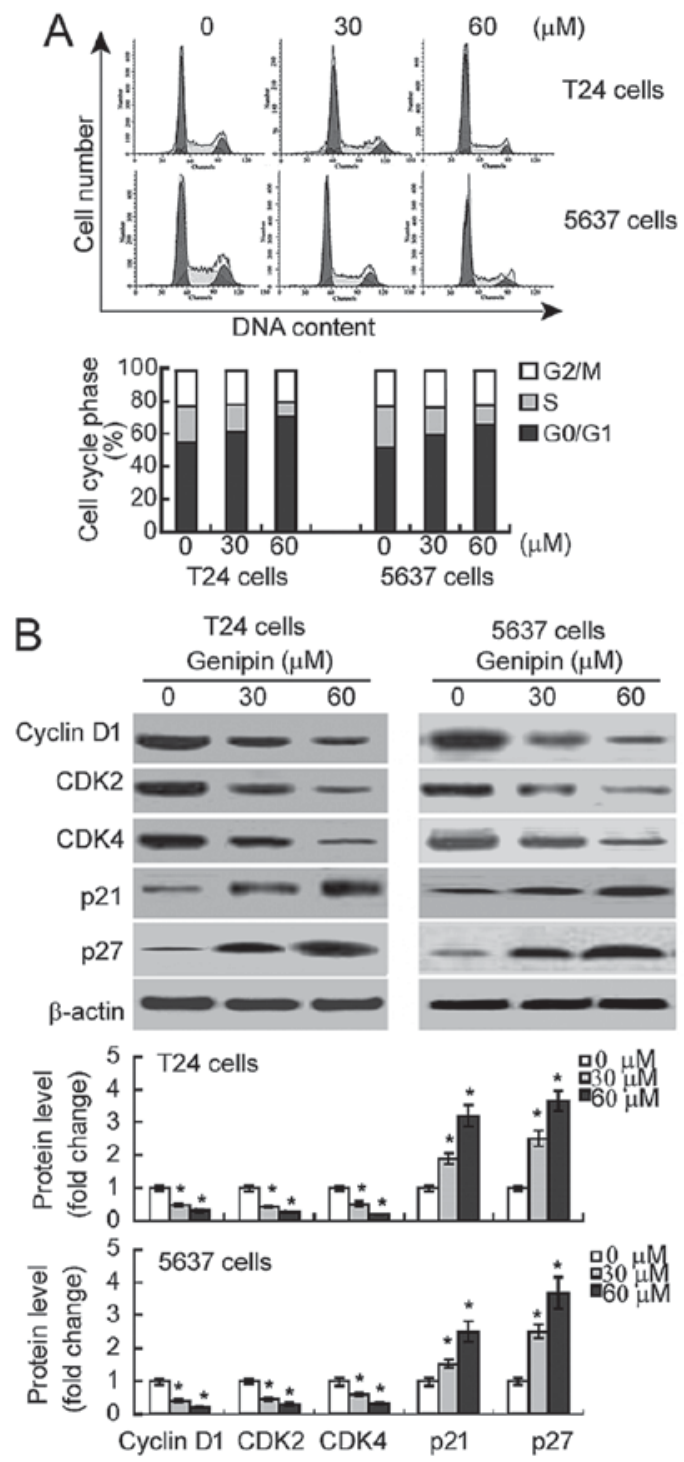

Figure 2. Genipin induces G0/G1 cell cycle arrest in bladder cancer cells. (A) Flow cytometry analysis of propidium iodide-stained cells following genipin treatment for $48 \mathrm{~h}$. Representative histograms of cell cycle distribution profiles are presented in the top panels. Bottom panels demonstrate quantification of the percentage of cells in each cell cycle phase. (B) Western blot analysis of indicated proteins in cells with or without genipin (30 or $60 \mu \mathrm{M})$. Bar graphs demonstrate densitometric analysis of western blots from three independent experiments. ${ }^{*} \mathrm{P}<0.05$ vs. vehicle-treated cells. CDK, cyclin-dependent kinase; p21, cyclin-dependent kinase inhibitor 1; p27, rabbit anti-cyclin-dependent kinase inhibitor 1B.

As reduced cell growth often occurs as a result of cell cycle arrest, the effect of genipin on cell cycle progression of bladder cancer cells was next examined. It was identified that genipin treatment induced a G0/G1 cell cycle arrest in T24 and 5,637 cells, as evidenced by an increase in the percentage of G0/G1-phase cells and a reduction in the percentage of S-phase cells. In agreement with these results, Cao et al (20) suggested that genipin induces cell cycle arrest at the G1 phase in HeLa human cervical carcinoma cells. Genipin has also been identified to induce G2/M-phase cell cycle arrest in AGS human gastric cancer cells (21) and human leukemia K562 cells (22). These results suggest that the growth suppressive activity of genipin is not cell cycle-specific. The data of the present study also suggested that genipin-mediated cell cycle 

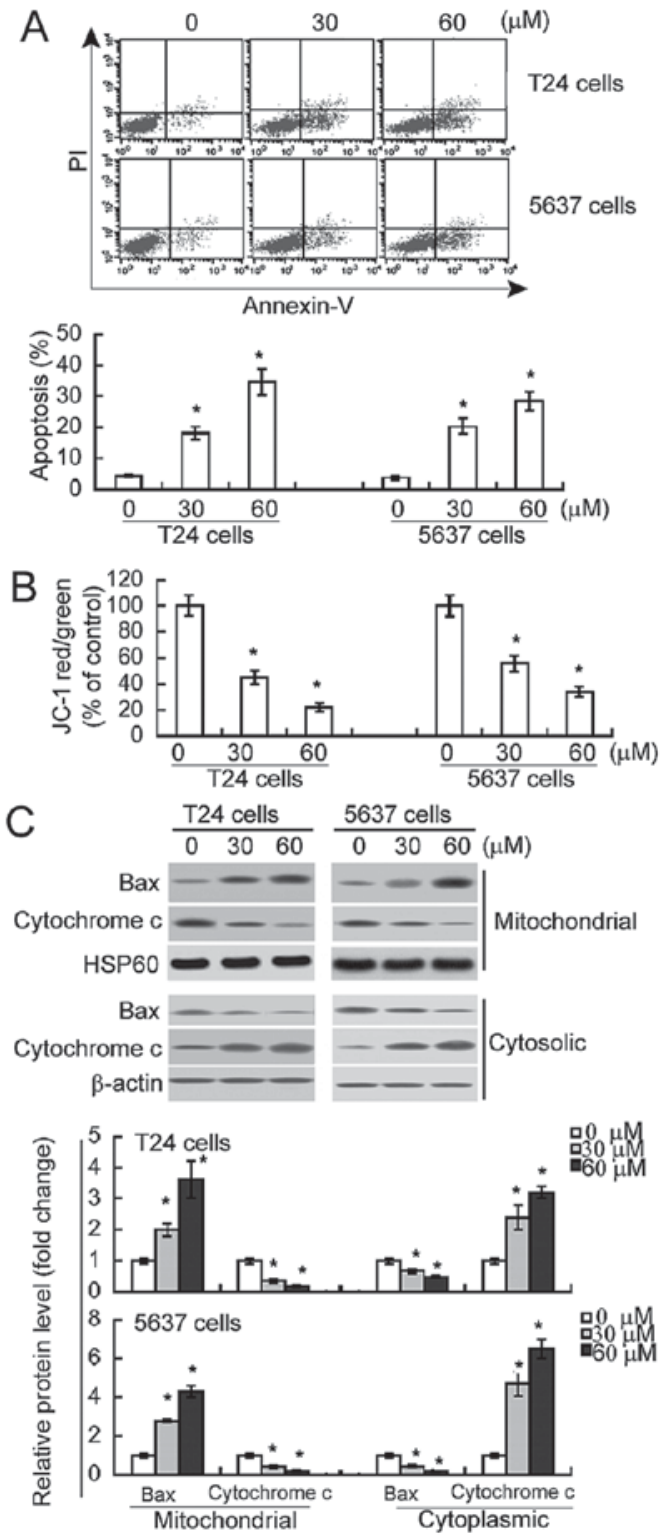

Figure 3. Genipin induces apoptosis of bladder cancer cells via the mitochondrial apoptotic cascade. (A) Flow cytometry analysis of apoptosis of bladder cancer cells with or without genipin treatment for $48 \mathrm{~h}$ following staining with Annexin V and PI. Representative dot plots of apoptosis are presented in top panels. Bar graphs represent quantification of apoptosis from three independent experiments. (B) Measurement of $\Delta \psi \mathrm{m}$ was performed by flow cytometry using JC-1 staining. Results are expressed as percentage of control values (assigned 100\%). (C) Western blot analysis of indicated proteins following genipin treatment ( 30 or $60 \mu \mathrm{M}$ ) for $48 \mathrm{~h}$. Bar graphs indicate densitometric analysis of western blots from three independent experiments ${ }^{*} \mathrm{P}<0.05$ vs. vehicle-treated cells. PI, propidium iodide; HSP60, heat shock protein 60; Bax, B-cell-2-like protein 4.

arrest may be ascribed to a reduction of cyclin D1, CDK2 and CDK4 expression, particularly the upregulation of p21 and p27. Increased p21 and p27 levels have been identified to interfere with the formation of $\mathrm{CDKs} / \mathrm{cyclin}$ complexes and prevent the cell cycle progression to $\mathrm{S}$ phase (23).

In addition to induction of cell cycle arrest, genipin demonstrated the ability to cause apoptosis in bladder cancer cells. In addition, genipin treatment resulted in mitochondrial depolarization and the release of mitochondrial cytochrome $c$ into the cytosol. The pro-apoptotic protein Bax has been documented

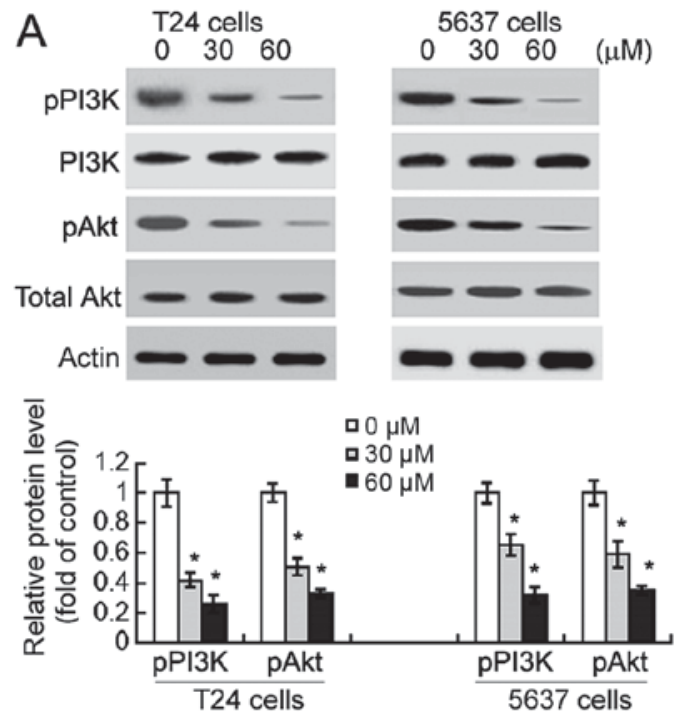

B
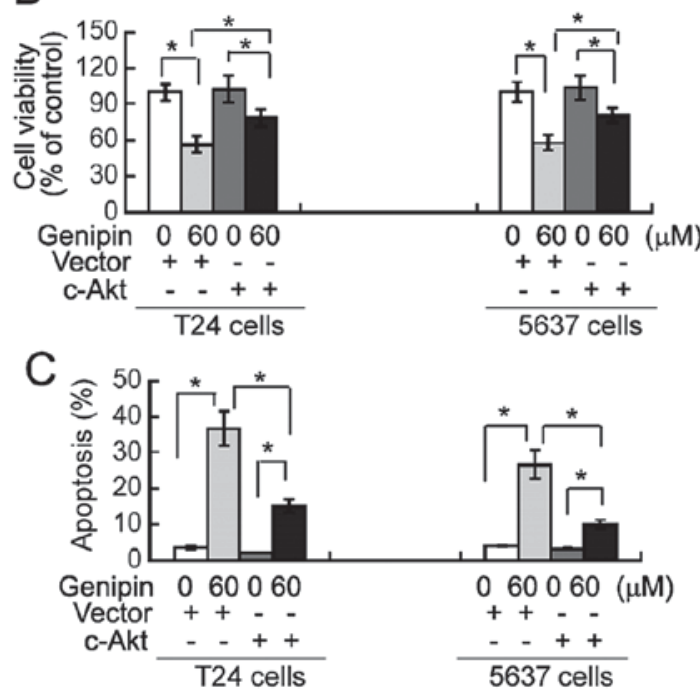

Figure 4. Inactivation of PI3K/Akt signaling mediates genipin-induced anticancer effects. (A) Western blot analysis of the phosphorylation of PI3K and Akt in bladder cancer cells with or without genipin (30 or $60 \mu \mathrm{M})$. Bar graphs indicate densitometric analysis of western blots from three independent experiments. ${ }^{*} \mathrm{P}<0.05$ vs. vehicle-treated cells. (B and C) Bladder cancer cells were transfected with active Akt-expressing plasmid or empty vector prior to exposure to $60 \mu \mathrm{M}$ genipin for $48 \mathrm{~h}$. (B) MTT assay was performed to test cell viability. (C) Flow cytometry analysis of apoptosis following Annexin V/propidium iodide staining. Bar graphs present data from three independent experiments. " $\mathrm{P}<0.05$ for indicated comparisons. PI3K, phosphoinositide-3 kinase; Akt, protein kinase B; pPI3K, phosphorylated PI3K; pAkt, phosphorylated Akt.

to translocate from the cytosol to the mitochondria in response to apoptotic stimuli, resulting in loss of $\Delta \psi \mathrm{m}$ and release of cytochrome $c$ (24). In the present study, it was observed that genipin-treated bladder cancer cells exhibited increased Bax levels in mitochondrial fractions and decreased Bax amounts in cytoplasmic fractions. Overall, genipin induced apoptosis in bladder cancer cells through Bax-mediated cytochrome $c$ release from the mitochondria. Similarly, induction of a mitochondrial apoptotic cascade has been described in non-small cell lung cancer H1299 cells following genipin treatment (25).

Inactivation of the PI3K/Akt pathway in genipin-treated bladder cancer cells was also observed in the present study, 
as evidenced by reduced phosphorylation levels of PI3K and Akt. The PI3K/Akt pathway is involved in the regulation of cancer cell growth and survival, and has been suggested as an important anticancer target (6). Qin et al (26) demonstrated that (-)-epigallocatechin-3-gallate, a component of green tea, promotes apoptosis in T24 bladder cancer cells through the inhibition of the PI3K/Akt pathway. Kim et al (27) revealed that naproxen [(S)-6-methoxy- $\alpha$-methyl-2-naphthaleneacetic acid] induces cell-cycle arrest and apoptosis in bladder cancer cells through the inhibition of PI3K activity. To confirm the role of the PI3K/Akt pathway in mediating the action of genipin, constitutively active Akt was overexpressed in bladder cancer cells prior to genipin exposure. Notably, it was observed that overexpression of constitutively active Akt reversed the effects of genipin on bladder cancer cell viability and apoptosis. Therefore, it may be suggested that the genipin-induced anticancer effects against bladder cancer cells are likely mediated through the inhibition of PI3K/Akt signaling.

In summary, genipin exerts growth-suppressive effects against bladder cancer cells via the induction of a $\mathrm{G} 0 / \mathrm{G} 1$ cell cycle arrest and mitochondrial apoptosis. These anticancer effects of genipin are largely ascribed to inhibition of the PI3K/Akt pathway. Genipin may represent a potential anticancer agent for bladder cancer.

\section{References}

1. Burger M, Catto JW, Dalbagni G, Grossman HB, Herr H, Karakiewicz P, Kassouf W, Kiemeney LA, La Vecchia C, Shariat S and Lotan Y: Epidemiology and risk factors of urothelial bladder cancer. Eur Urol 63: 234-241, 2013.

2. Mahdavifar N, Ghoncheh M, Pakzad R, Momenimovahed Z and Salehiniya H: Epidemiology, incidence and mortality of bladder cancer and their relationship with the development index in the world. Asian Pac J Cancer Prev 17: 381-386, 2016.

3. Ferlay J, Soerjomataram I, Dikshit R, Eser S, Mathers C, Rebelo M, Parkin DM, Forman D and Bray F: Cancer incidence and mortality worldwide: Sources, methods and major patterns in GLOBOCAN 2012. Int J Cancer 136: E359-E386, 2015.

4. Li S, Zeng XT, Ruan XL, Wang XH, Guo Y and Yang ZH: Simultaneous transurethral resection of bladder cancer and prostate may reduce recurrence rates: A systematic review and meta-analysis. Exp Ther Med 4: 685-692, 2012.

5. Vinall RL, Tepper CG, Ripoll AA, Gandour-Edwards RF, Durbin-Johnson BP, Yap SA, Ghosh PM and deVere White RW: Decreased expression of let-7c is associated with non-response of muscle-invasive bladder cancer patients to neoadjuvant chemotherapy. Genes Cancer 7: 86-97, 2016.

6. Cirone P, Andresen CJ, Eswaraka JR, Lappin PB and Bagi CM: Patient-derived xenografts reveal limits to PI3K/mTOR-and MEK-mediated inhibition of bladder cancer. Cancer Chemother Pharmacol 73: 525-538, 2014.

7. Wang Y, Leng H, Chen H, Wang L, Jiang N, Huo X and Yu B: Knockdown of UBE2T inhibits osteosarcoma cell proliferation, migration, and invasion by suppressing the PI3K/Akt signaling pathway. Oncol Res 24: 361-369, 2016.

8. Dong Q, Fu L, Zhao Y, Tan S and Wang E: Derlin-1 overexpression confers poor prognosis in muscle invasive bladder cancer and contributes to chemoresistance and invasion through PI3K/AKT and ERK/MMP signaling. Oncotarget 8: 17059-17069, 2017.

9. Alayev A, Salamon RS, Schwartz NS, Berman AY, Wiener SL and Holz MK: Combination of rapamycin and resveratrol for treatment of bladder cancer. J Cell Physiol 232: 436-446, 2017.
10. Nam KN, Choi YS, Jung HJ, Park GH, Park JM, Moon SK, Cho KH, Kang C, Kang I, Oh MS and Lee EH: Genipin inhibits the inflammatory response of rat brain microglial cells. Int Immunopharmacol 10: 493-499, 2010.

11. Wang GF, Wu SY, Rao JJ, Lü L, Xu W, Pang JX, Liu ZQ, Wu SG and Zhang JJ: Genipin inhibits endothelial exocytosis via nitric oxide in cultured human umbilical vein endothelial cells. Acta Pharmacol Sin 30: 589-596, 2009.

12. Zhang CY,Parton LE, Ye CP, Krauss S, Shen R, Lin CT, Porco JA Jr and Lowell BB: Genipin inhibits UCP2-mediated proton leak and acutely reverses obesity- and high glucose-induced beta cell dysfunction in isolated pancreatic islets. Cell Metab 3: 417-427, 2006.

13. Suzuki Y, Kondo K, Ikeda Y and Umemura K: Antithrombotic effect of geniposide and genipin in the mouse thrombosis model. Planta Med 67: 807-810, 2001.

14. Hughes RH, Silva VA, Ahmed I, Shreiber DI and Morrison B III: Neuroprotection by genipin against reactive oxygen and reactive nitrogen species-mediated injury in organotypic hippocampal slice cultures. Brain Res 1543: 308-314, 2014.

15. Wang N, Zhu M, Tsao SW, Man K, Zhang Z and Feng Y: Up-regulation of TIMP-1 by genipin inhibits MMP-2 activities and suppresses the metastatic potential of human hepatocellular carcinoma. PLoS One 7: e46318, 2012.

16. Wang R, MoYung KC,Zhao YJ and Poon K: A mechanism for the temporal potentiation of genipin to the cytotoxicity of cisplatin in colon cancer cells. Int J Med Sci 13: 507-516, 2016.

17. Perelman A, Wachtel C, Cohen M, Haupt S, Shapiro H and Tzur A: JC-1: Alternative excitation wavelengths facilitate mitochondrial membrane potential cytometry. Cell Death Dis 3: e430, 2012.

18. Singh AN, Baruah MM and Sharma N: Structure Based docking studies towards exploring potential anti-androgen activity of selected phytochemicals against Prostate Cancer. Sci Rep 7: $1955,2017$.

19. Koo HJ, Song YS, Kim HJ, Lee YH, Hong SM, Kim SJ, Kim BC, Jin C, Lim CJ and Park EH: Antiinflammatory effects of genipin, an active principle of gardenia. Eur J Pharmacol 495: 201-208, 2004.

20. Cao H, Feng Q, Xu W, Li X, Kang Z, Ren Y and Du L: Genipin induced apoptosis associated with activation of the c-Jun NH2-terminal kinase and p53 protein in HeLa cells. Biol Pharm Bull 33: 1343-1348, 2010.

21. Ko H, Kim JM, Kim SJ, Shim SH, Ha CH and Chang HI: Induction of apoptosis by genipin inhibits cell proliferation in AGS human gastric cancer cells via Egr1/p21 signaling pathway. Bioorg Med Chem Lett 25: 4191-4196, 2015.

22. Feng Q, Cao HL, Xu W, Li XR, Ren YQ and Du LF: Apoptosis induced by genipin in human leukemia K562 cells: Involvement of c-Jun N-terminal kinase in $\mathrm{G}_{2} / \mathrm{M}$ arrest. Acta Pharmacol Sin 32: 519-527, 2011.

23. Coqueret O: New roles for $\mathrm{p} 21$ and $\mathrm{p} 27$ cell-cycle inhibitors: A function for each cell compartment? Trends Cell Biol 13: 65-70, 2003.

24. Pastorino JG, Chen ST, Tafani M, Snyder JW and Farber JL: The overexpression of bax produces cell death upon induction of the mitochondrial permeability transition. J Biol Chem 273: 7770-7775, 1998

25. Yang X, Yao J, Luo Y, Han Y, Wang Z and Du L: P38 MAP kinase mediates apoptosis after genipin treatment in non-small-cell lung cancer H1299 cells via a mitochondrial apoptotic cascade. J Pharmacol Sci 121: 272-281, 2013.

26. Qin J, Xie LP, Zheng XY, Wang YB, Bai Y, Shen HF, Li LC and Dahiya R: A component of green tea, (-)-epigallocatechin-3-gallate, promotes apoptosis in T24 human bladder cancer cells via modulation of the PI3K/Akt pathway and Bcl-2 family proteins. Biochem Biophys Res Commun 354: 852-857, 2007.

27. Kim MS, Kim JE, Lim DY, Huang Z, Chen H, Langfald A, Lubet RA, Grubbs CJ, Dong Z and Bode AM: Naproxen induces cell-cycle arrest and apoptosis in human urinary bladder cancer cell lines and chemically induced cancers by targeting PI3K. Cancer Prev Res (Phila) 7: 236-245, 2014. 